http://jmscr.igmpublication.org/home/ ISSN (e)-2347-176x ISSN (p) 2455-0450

crossref DOI: https://dx.doi.org/10.18535/jmscr/v9i9.16

\title{
A Study on Biofilm Production and Its Association with Chronicity in Isolates Obtained From Various Types of Ulcers
}

\author{
Authors \\ Dr Joana Mary Magdaline ${ }^{1}$, Dr Akhila Aravind ${ }^{2 *}$ \\ ${ }^{1}$ Department of Microbiology, Government Medical College, Ernakulam, HMT colony PO, Kalamassery \\ Cochin, Kerala, India Pincode- 683503 \\ ${ }^{2}$ 15/205 City Hospital Lane, Thirunakkara, Kottayam, Kerala, India Pincode-686001 \\ *Corresponding Author \\ Dr Akhila Aravind
}

\begin{abstract}
Ulcers pose a significant affliction to our health care system. The prevalence of chronic ulcers in Indian population is much higher than that reported in the Western population. The healing of ulcers is affected by multiple systemic and local factors, among which biofilm formation by the pathogens is a therapeutic challenge. The present study was undertaken for a period of 1 year from February 2015 to find out the biofilm production status of the isolates \& to determine any association between biofilm production by the isolates and chronicity of the ulcer. In the present study, 66.9\% of the total isolates from various types of ulcers were biofilm producers. ${ }^{37}$ Gram positive bacteria were better biofilm producers in our study. Most frequent biofilm producers among Gram positives were Staphylococcus aureus \& among Gram negatives it was Pseudomonas aeruginosa. 74\% of isolates from ulcers of duration of $>3$ months were biofilm producers which was found to be a statistically significant association.
\end{abstract}

Keywords: ulcers, biofilm, chronicity.

\section{Introduction}

Ulcers are defined as wounds with a "full thickness depth" and a "slow healing tendency" which mainly occurs by endogenous mechanisms associated with predisposing conditions like Diabetes, venous insufficiency. In ulcers there is complete loss of the epidermis, portions of the dermis and even subcutaneous fat. Chronic ulcers are defined as wounds that have failed to proceed through the orderly process that produces satisfactory anatomic and functional integrity or that have proceeded through the repair process without producing an adequate anatomic and functional result ${ }^{1-5}$. Major types of chronic ulcers include. Diabetic foot ulcers,
Venous ulcers \& Pressure sores/Decubitus ulcers ${ }^{6}$. Healing of an ulcer is a dynamic process \& is mediated by interactive reactions of parenchymal cells, soluble mediators, blood elements, and extracellular matrix. This normal course is affected by various systemic as well as local factors which delays the healing and determines the chronicity of an ulcer ${ }^{7-12}$.

Another important mechanism by which bacteria interfere with the healing process by forming biofilms. Biofilms are bacterial populations that are enclosed in a matrix of extracellular polymeric substances (EPS). Biofilms may form from the accumulation of a single bacteria (monomicrobic 
aggregation) or from the accumulation of numerous species (polymicrobic aggregation) ${ }^{13}$. Chronic ulcers provide an ideal environment for biofilm formation. The necrotic tissue \& debris present in chronic ulcers allow bacterial attachment which form biofilms. ${ }^{14}$ Biofilms in ulcers produce an inflammatory response resulting in an infiltration of neutrophils \& macrophages surrounding the biofilm. It is hypothesised that the initiated inflammatory response is in favour of biofilm. By inducing an ineffective inflammatory response, the biofilm protects the bacteria contained in it and the increased exudate production serves as a source of nutrition, thereby helping to perpetuate the biofilm ${ }^{35}$.

The resistance of biofilm producing bacteria to antimicrobial agents starts from the attachment phase and increases with the development of the biofilm. The mechanisms involved include the following

1. Blocking-the matrix acts as a diffusion barrier to smaller molecules like antimicrobial agents.

2. Mutual protection- Different species of bacteria which in a biofilm can confer protection to each other.

3. By transfer of genes that confer antibiotic resistance between bacteria of same or different species.

4. Hibernation- another strategy of bacteria within the biofilms is going in to a state of hibernation or remaining quiescent. Most of the antimicrobial agents target on rapidly growing bacteria. Therefore hibernating bacteria in biofilms are unaffected by antibiotics. In the presence of antibiotics this antibiotic resistant strains will be selected out, which will multiply to become the dominant type among the bacterial population.

Thus, the treatment of ulcers infected with biofilm producing bacteria is a therapeutic challenge. The non-healing of such ulcers affect the patient adversely, both socially as well as financially.

\section{Relevance}

Epidemiological data available from the studies shows that the prevalence of chronic ulcer in Indian population is much higher than that seen in the Western population. In our institution also chronic ulcers is a significant burden. 44\% (377/849) of the total samples from the surgery department is from ulcers.

Biofilm formation by bacteria is an important feature in chronic ulcers. The biofilms prevent phagocytosis; they also act as diffusion barriers to penetration of antibiotics which contribute to the drug resistance exhibited by the infecting bacteria $\&$ can adversely affect the treatment. Therefore, the presence of bacterial biofilms in chronic ulcers may help us to explain the chronicity of ulcers and also, why an ulcer doesn't heal despite adequate antibiotic treatment as well as treatment for the underlying condition.

The morbidity \& mortality associated with such chronic ulcers can be dramatic. It is also associated with a high cost of healthcare, loss of productivity, and reduced quality of life and for a developing country like India this will cause severe health care burden. Therefore, prompt and appropriate management of the condition is needed to alleviate the consequences which can occur following a nonhealing of an ulcer; both medical as well as social. Studies on biofilm formation will give way to new arenas of research and may help us to develop new treatment modalities for tackling the same.

\section{Objectives}

1. To assess biofilm production of pathogenic bacteria associated with different types of ulcers.

2. To determine association between biofilm production and duration of ulcer.

\section{Materials \& Methods}

Study Design: Descriptive Study (Prevalence study) Study Setting: Department of Microbiology \& Department of Surgery

Study Period: 1 Year from January 2015/all samples collected during this period.

Sample Size: In a study done by Rahim et al to study the antimicrobial resistance among bacterial pathogens isolated from chronic ulcers in a tertiary 
care hospital in Pakistan, 50.9\% of the ulcers were positive for bacterial isolation. We had calculated sample size for our study using this prevalence in the formula $\mathrm{N}=4 \mathrm{pq} / \mathrm{D}^{2}$

$\mathrm{P}=50.9 \% \mathrm{q}=49.1 \%$.

Using an absolute precision (D) of $10 \%$, sample size was calculated to be 99. We had included all patients admitted in surgical wards with ulcers during the study period. Even though the minimum sample size calculated for our study was 99, we had included all 103 patients meeting the inclusion criteria, in our study.

Study Population: All patients admitted with ulcers in the surgical wards were included in the study.

Inclusion Criteria: A patient with ulcer was included only once during the period of study

Exclusion Criteria: Patients with malignant ulcers and ulcers associated with burns and post-operative wound infections were not included in the study.

Sampling Methodology: Universal sampling

Ethical Clearance: Obtained from the Institutional

Ethical Committee before commencement of the study (IEC 11/2014).

\section{Sample collection and Transport}

Several studies have demonstrated significant correlation between swab cultures \&biopsy specimen cultures in patients with ulcers. ${ }^{16,17}$. Hence we adopted swab cultures for our study.

Surrounding skin of the ulcer was disinfected with alcohol swabs .Ulcer area was thoroughly cleaned with sterile saline. Two sterile swabs were used for each patient. ${ }^{18,19}$ Samples were collected by making firm rotatory movements, covering entire area of the ulcer, holding both the swabs together. The swabs were then transported to the laboratory in sterile test tubes and processed within 2 hours. ${ }^{20-23}$

\section{Processing of the specimen}

Swabs with the specimens were inoculated on to culture media by streak culture method \& thioglycollate broth. Identification of the isolates up to species level was done as per standard microbiological methods. Antibiotic sensitivity testing was done for the above isolates using Kirby - Bauer Disc Diffusion technique according to standard microbiological methods. All the above isolates were subjected to the test for biofilm detection. We had chosen the Tissue culture plate method for detecting biofilm production by the isolates.

\section{Tissue culture plate method}

- Bacterial isolates were sub-cultured on to nutrient agar.

- Incubated the same for overnight at $37^{\circ} \mathrm{C}$

- From the growth on nutrient agar obtained after overnight incubation a loopful of the isolate was inoculated into Trypticase soy broth with $1 \%$ glucose.

- The broth was incubated at $37^{0} \mathrm{C}$ for 24 hours

- After incubation $1 \mathrm{ml}$ of broth was diluted in $100 \mathrm{ml}$ of sterile un-inoculated TSB with $1 \%$ glucose

- $0.2 \mathrm{ml}$ from the diluted broth culture was transferred into each well of 96 well sterile flat bottom tissue culture plate (Nest, Tarson).

- $0.2 \mathrm{ml}$ each of positive and negative control (treated like the isolates) were also included every time the test was done.

o Positive control used was Klebsiella spp\& negative control was coagulase negative staphylococci

o The controls used were obtained from a pilot study done on bacterial isolates from ulcers. These were tested for biofilm production repeatedly and the results were consistent. Hence, we had used these as the positive \& negative controls for each test batch

- $0.2 \mathrm{ml}$ of un-inoculated sterile TSB with $1 \%$ glucose was inoculated into the well of each plate, which served as the control to check sterility and non-specific binding of the media.

- Tissue culture plates were covered with the lid provided\& incubated at $37{ }^{\circ} \mathrm{C}$ for 24 hours.

- After 24 hours broth in the plates were 
decanted off into a discard jar containing disinfectant.

Each well was washed three times with approximately $300 \mu \mathrm{l}$ of phosphate buffered saline

Then $0.25 \mathrm{ml}$ of methanol was added to each well \&kept at room temperature for 15 minutes.

- Wells were then stained by adding $0.2 \mathrm{ml}$ of crystal violet $(0.1 \% \mathrm{w} / \mathrm{v})$ to each well and left for 20 minutes- Adherent bacterial cells were uniformly stained with crystal violet.

- Excess stain was removed by repeated washing (3 times) using approximately $300 \mu \mathrm{l}$ of sterile distilled water for each well

- Plates were then dried by keeping it in an inverted position on absorbent paper

- Finally, $0.2 \mathrm{ml}$ of $33 \%$ glacial acetic acid was added to each well to extract the absorbed stain from the adherent cells

- The optical density (OD) of the stained wells were then measured using a Bio Rad ELISA reader at $490 \mathrm{~nm}$

- All the isolates including controls were tested in duplicate and average of the OD values taken.

- To compensate for background absorbance, average of OD readings from sterile medium were taken and subtracted from all test values to get the final OD value.

- Depending on these OD values, bacteria were considered as biofilm producer or nonproducer. $^{24}$

The cut off OD value to assess biofilm producing status is given in the table below

Table 1: Cut off optical density value for biofilm production $^{25,26}$

\begin{tabular}{|l|l|}
\hline Od Value & Biofillm Status \\
\hline$<\mathbf{0 . 1 2}$ & Non/weak producer \\
\hline $\mathbf{> 0 . 1 2}$ & Producer \\
\hline
\end{tabular}

Test was repeated for all isolates to prove reproducibility of the test method.

\section{Data entry}

History and clinical details obtained from each patient was numerically coded and entered into
Microsoft excel spread sheet. The status of biofilm production by the isolates were also coded \& entered into excel spread sheet.

\section{Data analysis}

Chi square test \& Fishers exact test were used in the analysis of study variables. The level of statistical significance was taken as $\mathrm{p}$ Value $<0.05$. Statistical significance was analysed using Statistical package for Social Sciences (SPPS) software16.0.

\section{Results}

The present study was conducted at the Departments of Microbiology \& Surgery over a period of one year starting from $1^{\text {st }}$ of February 2015. A total of 103 samples were collected from patients with different types of ulcers. The mean age of patients who were included in the study was calculated to be 55+/- 12 years. Males were predominant in our study population compared to females.

\section{Category of Ulcers in the Study}

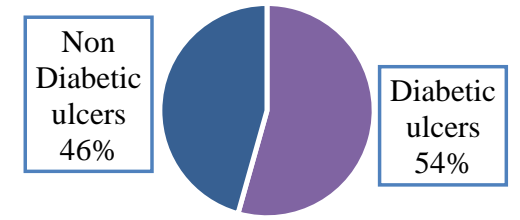

- Diabetic ulcers - Non Diabetic ulcers

Figure 1: Pie diagram showing the proportion of types of ulcers in the study population

- Of the 103 cases 56 patients had diabetic ulcers, out of which 10 had smoking $\& 8$ had alcoholism as an additional risk factor.

- Non-diabetic ulcers were 47 in number which included,

- 15 varicose ulcers of which 4 had diabetes \& 11 had alcoholism, also as a predisposing factors.

- 11 decubitus ulcers. 


\section{JMSCR Vol||09||Issue||09||Page 83-91||September}

Table 2 : Table showing the frequency of various isolates obtained from major types of ulcers in the study

\begin{tabular}{|l|c|c|c|}
\hline Bacteria & $\begin{array}{c}\text { Varicose } \\
\text { ulcer }\end{array}$ & $\begin{array}{c}\text { Diabetic } \\
\text { ulcer }\end{array}$ & $\begin{array}{c}\text { Decubitus } \\
\text { ulcer }\end{array}$ \\
\hline Staphylococcus aureus & 8 & 20 & 4 \\
\hline Pseudomonas aeruginosa & 7 & 10 & 4 \\
\hline Enterococcus spp & 0 & 8 & 0 \\
\hline Escherichia coli & 1 & 5 & 1 \\
\hline Proteus spp & 0 & 6 & 1 \\
\hline Klebsiella pneumoniae & 1 & 6 & 2 \\
\hline Acinetobacter spp & 0 & 3 & 1 \\
\hline Corynebacterium spp & 1 & 8 & 0 \\
\hline Serratia spp & 0 & 3 & 0 \\
\hline Morganella Morgagni & 2 & 1 & 0 \\
\hline Flavobacterium spp & 0 & 1 & 0 \\
\hline Enterobacter spp & 0 & 2 & 0 \\
\hline Streptococcus spp & 0 & 4 & 0 \\
\hline Coliform bacilli & 1 & 3 & \\
\hline CoNS & 0 & 2 & \\
\hline
\end{tabular}

\section{Bacterial Flora in Diabetic Ulcer}

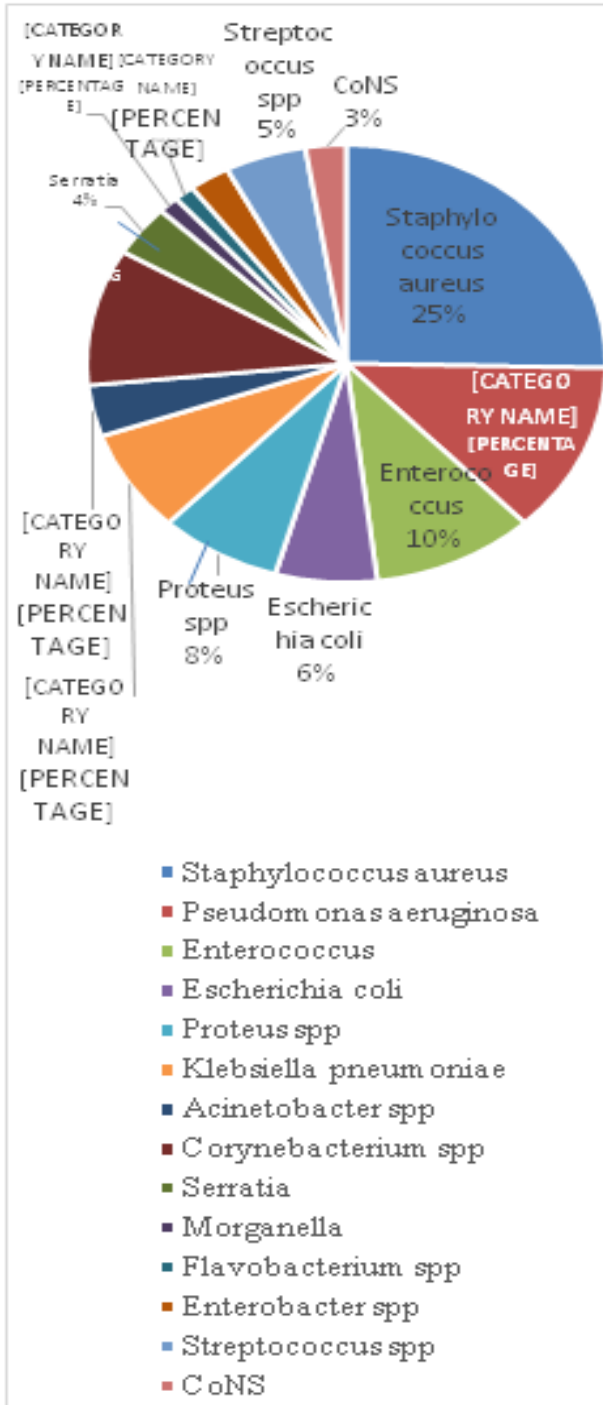

Figure 2: Bacterial flora obtained in patients with diabetes ulcer
- Monomicrobial infection in 37 cases $(66 \%)$ $\&$ polymicrobial infection was seen in 19 cases $(34 \%)$

- In monomicrobial infections Gram positives were present in $51 \%$ \& Gram negative in $49 \%$ of patients

- In polymicrobial infections Gram positive \&Gram-negative infection were present in $45 \%$ \& $55 \%$ respectively.

- Commonest Gram-positive isolate in both polymicrobial \& monomicrobial infection was Staphylococcus aureus \& Pseudomonas aeruginosa being the commonest Gramnegative isolate in both types.

\section{Biofilm Production by Isolates}

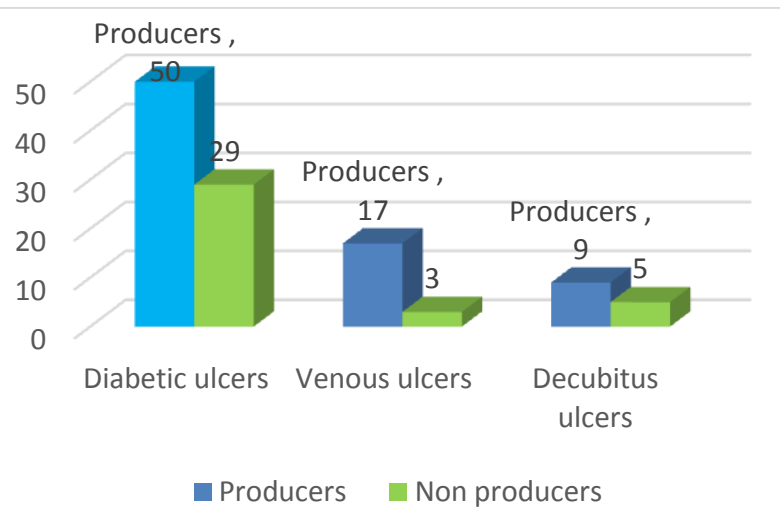

Figure 3: Biofilm production status of isolates from various types of ulcers

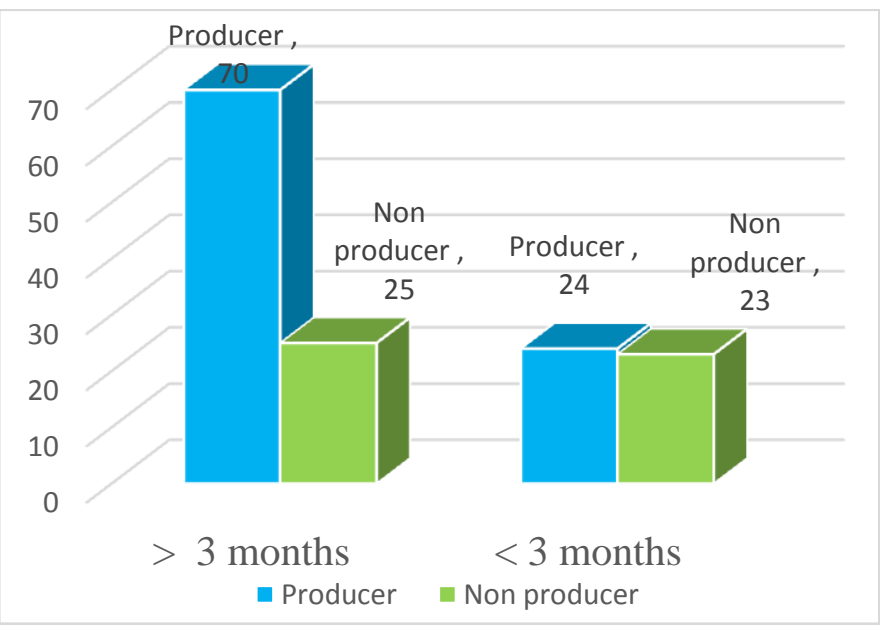

Figure 4: Bar diagram showing association between Biofilm Status \& Duration of ulcer 
- $63 \%$ of isolates from diabetic ulcers, $85 \%$ of venous ulcer isolates \& $64 \%$ of isolates from decubitus ulcers were biofilm producers.

- There was no statistically significant association between type of ulcers \& biofilm production by isolates obtained from them which was assessed using Chi square test and $\mathrm{p}$ value obtained was 0.102 . (>0.05)

- The association between biofilm status and duration of ulcer was assessed using Chi Square test and the $\mathrm{p}$ value obtained for the same was $0.002(<0.05)$ and this association was found to be significant statistically.

\section{Discussion}

Ulcers especially chronic ulcers pose a significant health care burden worldwide. It also causes major social as well as economic problem to the affected individual. The non- healing of such ulcers could be due to multiple factors among which bacterial infections are the forerunners. Infection with MDR bacteria as well as biofilm production by bacteria prevent healing process in ulcers

The present study was conducted in the Department of Microbiology \& Department of Surgery over a period of 1 year starting from February 1, 2015 ,since regional studies comparing the flora of the major types of ulcers were few \& literature search didn't reveal any studies assessing the biofilm status of the bacteria isolated from ulcers from our region. The principal aimof this study was to identify the predominant bacteriological flora, to find out the biofilm production status of the isolates $\&$ to determine any association between biofilm production by the isolates and chronicity of the ulcer

The study population in the present study included patients from the age of 25 to those up to the age of 87. Maximum number of patients were from the age group 51-60.This data was in accordance with the observation from other studies ${ }^{27-33}$ The mean age in other studies on ulcers also lies in the range of $55+$ / - 13 years.

We had a male predominance among our study population. This was in accordance with the studies on ulcers from India $^{28-34}$ but studies from outside India especially from the West ${ }^{27,35}$ had reported that women were twice likely to get affected with ulcers than men.

Biofilm production by bacteria impedes healing of an ulcer which contribute to the chronicity of an ulcer. Non -healing can be because of the evasion of the host immune response by the isolate as well as poor penetration of antibiotics. In the present study $66.9 \%$ of the total isolates from ulcers were biofilm producers. In other studies assessing biofilm status also, $>60 \%$ of the isolates were found to be biofilm producers. ${ }^{28,36,37}$ Gram positive bacteria were better biofilm producers in our study which was in discordance with other studies which have reported Gram negative bacteria as better biofilm producers ${ }^{37}$. In the present study $72.7 \%$ of MRSA were biofilm producers whereas in a study by Rahim et al at Pakistan had shown that all MRSA isolates were biofilm producers ${ }^{36}$. Most frequent biofilm producers among Gram negatives were Pseudomonas aeruginosa \& among Gram positives was Staphylococcus aureus in our study. Study by Swarna et $\mathrm{al}^{37}$ also has similar findings, but Zubair et al had reported Proteus vulgaris as the predominant producer. ${ }^{28}$ Other isolates in our study like Enterococcus spp, Proteus spp, Escherichia coli, Klebsiella pneumoniae, Serratia, Morganella, Streptococcus \& CoNS which were lesser in number were also biofilm producers.

In our study $74 \%$ of isolates from ulcers of duration of $>3$ months were biofilm producers which was found to be a statistically significant association. This was in agreement with study done by Zubair et $\mathrm{al}^{28}$ who also reported a statistically significant association between duration of ulcer \& biofilm status. In the study by James et $\mathrm{al}^{38}$ at Texas, they had found that more than $60 \%$ of chronic ulcers were harbouring biofilm producing bacteria.

More multi centric studies should be conducted to assess the biofilm production status of isolates from ulcers to know the extent of the problem. Increased prevalence of biofilm producing isolates would necessitate development \& inclusion of new strategies to prevent biofilm formation like 
prevention of attachment \& prevention of development of biofilms in the treatment plan of chronic ulcers. ${ }^{39}$

\section{Limitations of the Study}

ATCC control strains for biofilm production was not used as positive \& negative controls as they were not available for purchase at the time of study; instead an in house positive \& negative controls were used which gave consistent results on repeated testing.

\section{Conclusion}

- $63 \%$ of isolates from diabetic ulcers, $85 \%$ of venous ulcer isolates \& $64 \%$ of isolates from decubitus ulcers were biofilm producers.

- There was no statistically significant association between type of ulcers \& biofilm production by isolates obtained from them which were assessed using Chi square test and $\mathrm{p}$ value obtained was 0.102 . (>0.05)

- Majority of the biofilm producing bacteria were isolated from ulcers with duration more than 3 months \& this association was statistically significant. This observation was shared by another similar study by Zubair et al at Aligarh.

\section{References}

1. Siddiqui AR, Bernstein JM. Chronic wound infection: Facts and controversies. ClinDermatol. 2010 Sep; 28(5):519-26.

2. de Souza JM, Vieira EC, Cortez TM, Mondelli AL, Miot HA, Abbade LPF. Clinical and microbiologic evaluation of chronic leg ulcers: a cross-sectional study. Adv Skin Wound Care. 2014;27(5):222-227.

3. Renuka Sharma, R K Sharma, Pradeep Goyal, Ashok Sharma, Monique Suresh, Saurav. Review of chronic leg ulcers over a period of one year in a tertiary care hospital in North India. Sch. J. App. Med. Sci., 2016; 4(4D):1392-1397

4. Courtney M. Townsend, Daniel Beauchamp, B. Mark Evers, Kenneth L. Mattox. Sabiston Textbook of Surgery, The molecular basis of modern surgical practice. 19th ed. Elsevier: 165.

5. F .Charles. Brunicardi, Dana .K. Anderson, Timothy .R. Billar, David. L. Dunn, John .G. Hunter, Jeffrey .B. Mathews. Schwartz Principles of surgery. In: 9th edition. McGraw hill: 224.

6. Kirketerp-Møller K, Zulkowski K, James G. Chronic Wound Colonization, Infection, and Biofilms. In: Bjarnsholt T, Jensen PØ, Moser C, Høiby N, editors. Biofilm Infections [Internet]. New York, NY: Springer New York; 2011 [cited 2016 Jun 26]. p. 11-24. Available from: http://link.springer.com/10.1007/978-1-44196084-9_2

7. Courtney M. Townsend, Daniel Beauchamp, B. Mark Evers, Kenneth L. Mattox. Sabiston Textbook of Surgery, The molecular basis of modern surgical practice. 19th ed. Elsevier : 151-164

8. F. Charles. Brunicardi, Dana .K. Anderson, Timothy .R. Billar, David. L. Dunn, John .G. Hunter, Jeffrey .B. Mathews. Schwartz Principles of surgery. In: 9th edition. McGraw hill :219

9. F. Charles. Brunicardi, Dana .K. Anderson, Timothy .R. Billar, David. L. Dunn, John .G. Hunter, Jeffrey .B. Mathews. Schwartz Principles of surgery. In: 9th edition. McGraw hill

10. Williams NS, Bulstrode CJK, O'Connell PR, Bailey H, Love RJM. Bailey \& Love's short practice of surgery, $26^{\text {th }}$ edition London: Hodder Arnold; 2008: 24-25

11. Bowler PG, Duerden BI, Armstrong DG. Wound Microbiology and Associated Approaches to Wound Management. Clin Microbiol Rev. 2001 Apr 1;14(2): 244-69.

12. F. Charles. Brunicardi, Dana. K. Anderson, Timothy .R. Billar, David. L. unn, John. G. Hunter, Jeffrey .B. Mathews. Schwartz Principles of surgery. In: 9th edition. McGraw hill: 222-224. 
13. Mandell GL, Bennett JE, Dolin R, editors. Mandell, Douglas, and Bennett's principles and practice of infectious diseases. 7th ed. Philadelphia, PA: Churchill Livingstone/Elsevier; 2010: 23-24

14. Zhao G, Usui ML, Lippman SI, James GA, Stewart PS, Fleckman P, et al. Biofilms and Inflammation in Chronic Wounds. Adv Wound Care. 2013 Sep;2(7):389-99.

15. Mandell GL, Bennett JE, Dolin R, editors. Mandell, Douglas, and Bennett's principles and practice of infectious diseases. 7th ed. Philadelphia, PA: Churchill Livingstone/Elsevier; 2010. 23-24 p.

16. Bowler PG, Duerden BI, Armstrong DG. Wound Microbiology and Associated Approaches to Wound Management. Clin Microbiol Rev. 2001 Apr 1;14(2): 244-69.

17. Miller CN, Carville K, Newall N, Kapp S, Lewin G, Karimi L, et al. Assessing bacterial burden in wounds: comparing clinical observation and wound swabs. Int Wound $\mathrm{J}$. 2011;8(1):45-55.

18. Reddy M, Gill SS, Wu W, Kalkar SR, Rochon PA. Does This Patient Have an Infection of a Chronic Wound? JAMA. 2012 Feb 8;307 (6):605-11.

19. Marie S. Tuttle. Association Between Microbial Bioburden and Healing Outcomes in Venous Leg Ulcers: A Review of the Evidence. Wound Heal Soc. Advances In Wound Care, Volume 4, Number 1.

20. Patricia M. Tille. Bailey \& Scott's Textbook of Diagnostic Microbiology.13 ${ }^{\text {th }}$ edition. Mosby/Elsevier: 969-971.

21. Connie .R .Mahon, George Manuselis, Textbook of Diagnostic Microbiology, $2^{\text {nd }}$ edition, Saunders : 239,263.

22. Henry. D. Isenberg, Clinical Microbiology Procedures Handbook, American Society for Microbiologists, Volume 1 :1.16.4.

23. Washington Winn Jr, Allen S, William Janda, Koneman E, Gary Procop, Schrekenberger P, et al. Koneman'sColor Atlas and Textbook of
Diagnostic Microbiology. 6th ed. Lippincott Williams \& Wilkins: 96

24. Deka V. Comparison of Tissue Culture plate method, Tube Method and Congo Red Agar Method for the detection of biofilm formation by Coagulase Negative Staphylococcus isolated from Non-clinical Isolates. Int J Curr Microbiol App Sci. 2014;3(10):810-815.

25. Oliveira A, Cunha M de LR. Comparison of methods for the detection of biofilm production in coagulase-negative staphylococci. BMC Res Notes. 2010;3:260.

26. de Castro Melo P, Ferreira LM, Filho AN, Zafalon LF, Vicente HIG, de Souza V. Comparison of methods for the detection of biofilm formation by Staphylococcus aureus isolated from bovine subclinical mastitis. Braz J Microbiol. 2013 May 17;44(1):119-24.

27. Perim MC, Borges $\mathrm{J}$ da C, Celeste SRC, Orsolin E de F, Mendes RR, Mendes GO, et al. Aerobic bacterial profile and antibiotic resistance in patients with diabetic foot infections. Rev Soc Bras Med Trop. 2015 Oct;48(5):546-54.

28. Zubair M, Malik A, Ahmad J, Rizvi M, Farooqui KJ, Rizvi MW. A study of biofilm production by Gram negative organisms isolated from diabetic foot ulcer patients. Biol Med. 2011;3(2):147-57.

29. Anandi C, Alaguraja D, Natarajan V, Ramanathan M, Subramaniam CS, Thulasiram $\mathrm{M}$, et al. Bacteriology of diabetic foot lesions. Indian J Med Microbiol. 2004;22(3):175.

30. Zubair M, Malik A, Ahmad J, others. Clinicobacteriology and risk factors for the diabetic foot infection with multidrug resistant microorganisms in north India. Biol Med. 2010;2(4):22-34.

31. Tiwari S, Pratyush DD, Dwivedi A, Gupta SK, Rai M, Singh SK. Microbiological and clinical characteristics of diabetic foot infections in northern India. J Infect Dev Ctries. 2012;6(4):329-332.

32. Sugandhi P, Arvind Prasanth D. Microbiological profile of bacterial pathogens 
from diabetic foot infections in tertiary care hospitals, Salem. Diabetes MetabSyndrClin Res Rev. 2014 Jul;8(3):129-32.

33. Umadevi S, Kumar S, Joseph NM, Easow JM, Kandhakumari G, Srirangaraj $\mathrm{S}$, et al. Microbiological Study of Diabetic Foot Infections. Indian J Med Spec. 2011 Feb 21;2(1).

34. Shukla VK, Ansari MA, Gupta SK. Wound healing research: A perspective from India. Int J Low Extrem Wounds. 2005;4:7-8.

35. Mekkes J, Loots MAM, Van Der Wal AC, Bos JD. Causes, investigation and treatment of leg ulceration. Br J Dermatol. 2003;148(3):388401.

36. Rahim K, Qasim M, Rahman H, Khan TA, Ahmad I, Khan N, et al. Antimicrobial resistance among aerobic biofilm producing bacteria isolated from chronic wounds in the tertiary care hospitals of Peshawar, Pakistan. J Wound Care. 2016 Aug;25(8):480-6.

37. S.R.Swarna, RadhaMadhavan, S.Gomathi, Devaraj, S. Thamaraiselvi. A study of biofilm on diabetic foot ulcer. Int J Res Pharm Biomed Sci. 3(4):1809-12.

38. James GA, Swogger E, Wolcott R, Pulcini E deLancey, Secor P, Sestrich J, et al. Biofilms in chronic wounds. Wound Repair Regen. 2008 Jan;16(1):37-44.

39. Chen M, Yu Q, Sun H. Novel Strategies for the Prevention and Treatment of Biofilm Related Infections. Int J Mol Sci. 2013 Sep 6;14(9):18488-501. 